\title{
3D CFD Simulations of MOCVD Synthesis System of Titanium Dioxide Nanoparticles
}

\author{
Siti Hajar Othman, ${ }^{1,2}$ Suraya Abdul Rashid, \\ Tinia Idaty Mohd Ghazi, ${ }^{2}$ and Norhafizah Abdullah ${ }^{2}$ \\ ${ }^{1}$ Department of Food and Process Engineering, Faculty of Engineering, University Putra Malaysia, 43400 Serdang, Selangor, Malaysia \\ ${ }^{2}$ Department of Chemical and Environmental Engineering, Faculty of Engineering, University Putra Malaysia, 43400 Serdang, \\ Selangor, Malaysia \\ ${ }^{3}$ Advanced Materials and Nanotechnology Laboratory, Institute of Advanced Technology, University Putra Malaysia, 43400 Serdang, \\ Selangor, Malaysia
}

Correspondence should be addressed to Siti Hajar Othman; s.hajar@eng.upm.edu.my

Received 7 June 2013; Accepted 2 September 2013

Academic Editor: Huogen Yu

Copyright (C) 2013 Siti Hajar Othman et al. This is an open access article distributed under the Creative Commons Attribution License, which permits unrestricted use, distribution, and reproduction in any medium, provided the original work is properly cited.

\begin{abstract}
This paper presents the 3-dimensional (3D) computational fluid dynamics (CFD) simulation study of metal organic chemical vapor deposition (MOCVD) producing photocatalytic titanium dioxide $\left(\mathrm{TiO}_{2}\right)$ nanoparticles. It aims to provide better understanding of the MOCVD synthesis system especially of deposition process of $\mathrm{TiO}_{2}$ nanoparticles as well as fluid dynamics inside the reactor. The simulated model predicts temperature, velocity, gas streamline, mass fraction of reactants and products, kinetic rate of reaction, and surface deposition rate profiles. It was found that temperature distribution, flow pattern, and thermophoretic force considerably affected the deposition behavior of $\mathrm{TiO}_{2}$ nanoparticles. Good mixing of nitrogen $\left(\mathrm{N}_{2}\right)$ carrier gas and oxygen $\left(\mathrm{O}_{2}\right)$ feed gas is important to ensure uniform deposition and the quality of the nanoparticles produced. Simulation results are verified by experiment where possible due to limited available experimental data. Good agreement between experimental and simulation results supports the reliability of simulation work.
\end{abstract}

\section{Introduction}

To date, titanium dioxide $\left(\mathrm{TiO}_{2}\right)$ nanoparticles have been attracting extensive attention due to their high photocatalytic activity [1], special optical properties [2], and enhanced mechanical properties [3]. $\mathrm{TiO}_{2}$ nanoparticles have been used widely for industrial applications such as photocatalysts [4], anti-UV agent [5], ceramics [6], sensors [7], and solar energy conversion [8]. They offer extra benefits of high stability, low cost, nontoxicity, hydrophilicity, and a high refractive index.

Many methods have been employed to synthesize $\mathrm{TiO}_{2}$ nanoparticles and among them metal organic chemical vapor deposition (MOCVD) is a promising technique for nanoparticles production due to its relative low cost and simplicity of the process. MOCVD allows control of particle size, size distribution, and crystal structure of the synthesized nanoparticles by controlling operation parameters such as deposition temperature and carrier gas flow rate [9]. The use of metal organic compound precursor that has relatively low decomposition temperature and high volatility enables the experiment to be carried out at low temperature and pressure [10]. Furthermore, MOCVD has the potential to be scaled up to industrial scale production levels.

However, regardless of the promising advantages of using MOCVD for the synthesis of $\mathrm{TiO}_{2}$ nanoparticles, actual process is still not completely understood. The understanding of fluid dynamics inside MOCVD reactor during synthesis process is important to provide groundwork for future development of MOCVD processes and reactors. This can be achieved by utilizing computational fluid dynamics (CFD) simulation. CFD simulation offers valuable insight into the flow behavior of reactant and product gases inside MOCVD 


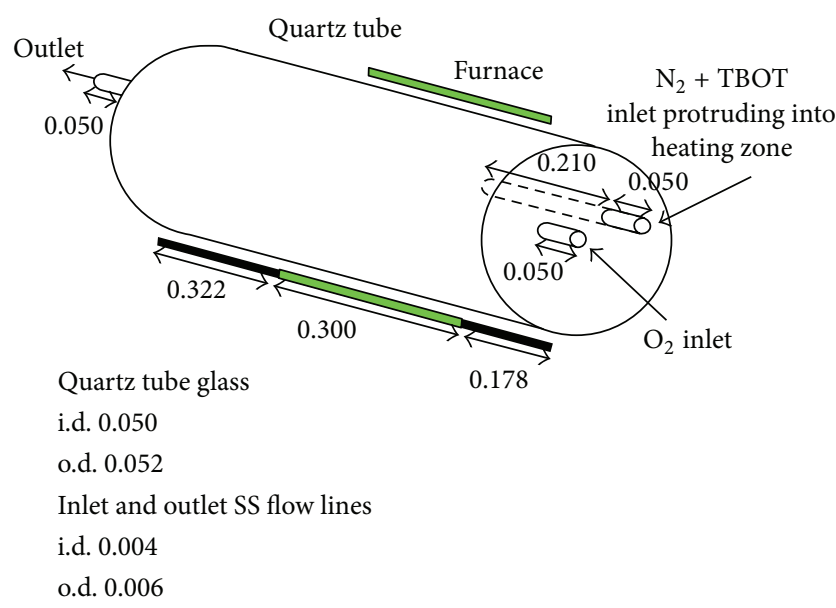

FIGURE 1: Geometry of the MOCVD reactor and its schematic representation. All the measurements are in metre $(\mathrm{m})$.

reactor, which is important to understand nanoparticle formation, amount of yield, and deposition location.

A glance through the literature reveals that reported CFD studies of $\mathrm{TiO}_{2}$ deposition using MOCVD have been limited to deposition of $\mathrm{TiO}_{2}$ thin films in vertical configuration cold wall CVD reactors [11-14]. Almost all the models were simplified to a 2-dimensional (2D) model due to either the axisymmetric shape of reactor or for simplicity reasons. The literature clearly lacks study regarding 3-dimensional (3D) CFD on deposition of $\mathrm{TiO}_{2}$ nanoparticles using a horizontal configuration hot wall MOCVD reactor. 3D CFD study is especially important to simulate any nonaxisymmetric geometry of the MOCVD reactor such as the case of reactor employed in the current study. Modelling different configurations and types of MOCVD reactor could provide valuable insight for future improvement towards optimizing the MOCVD processes and reactors. This is crucial for production of $\mathrm{TiO}_{2}$ nanoparticles in order to become one of the industrially important materials. Furthermore, present study takes the opportunity to analyze $\mathrm{TiO}_{2}$ nanoparticles deposited using titanium (IV) butoxide (TBOT) precursor since many of the previous studies used titanium isopropoxide (TTIP) as the precursor although TBOT has been proved to produce purer $\mathrm{TiO}_{2}$ crystalline structure [15], with smaller and more uniform grain size than TTIP $[15,16]$.

The aim of this study was to investigate and understand the fluid dynamics inside MOCVD synthesis system particularly on deposition process of $\mathrm{TiO}_{2}$ nanoparticles in a horizontal configuration hot wall reactor using TBOT precursor. The 3D model was simulated to predict temperature, velocity, gas streamline, mass fraction of reactants and products, kinetic rate of reaction, and surface deposition rate profiles inside the reactor.

\section{Experimental}

2.1. Reactor Configuration. The simulation was run for a 3D model horizontal hot wall MOCVD reactor which has been used to synthesize photocatalytic $\mathrm{TiO}_{2}$ and iron (Fe) doped $\mathrm{TiO}_{2}$ nanoparticles reported elsewhere [17-20]. The MOCVD reactor setup has been simplified to consist of stainless steel gas flow lines $(0.004 \mathrm{~m}$ inside diameter (i.d.) and $0.006 \mathrm{~m}$ outside diameter (o.d.)) with 2 inlets and 1 outlet and a horizontal quartz tube $(0.800 \mathrm{~m}$ long, $0.050 \mathrm{~m}$ i.d., and $0.052 \mathrm{~m}$ o.d.) fitted into a split tube furnace where the heating zone was $0.300 \mathrm{~m}$ long. Note that the inlet which carried a mixture of TBOT precursor and nitrogen $\left(\mathrm{N}_{2}\right)$ carrier gas is protruded, extending into the heating zone to ensure that precursor is thermally decomposed at temperature as close as possible to the heating zone temperature. Schematic diagram of the reactor setup can be seen in Figure 1.

2.2. Reactions. The volumetric (homogeneous) and surface (heterogeneous) reactions considered in the present study were proposed to consist of thermal decomposition, hydrolysis, and surface depositions of $\mathrm{TBOT}$ and $\mathrm{TiO}_{2}$ in gas phase $\left(\mathrm{TiO}_{2}(\mathrm{~g})\right)$ as listed in Table 1 . The reactions were proposed based on the literature for the study of $\mathrm{TiO}_{2}$ thin films deposited using TTIP [21, 22].

Above thermal decomposition temperature of TBOT, homogeneous gas phase reaction occurs inside the reactor. TBOT undergoes thermal decomposition resulting in $\mathrm{TiO}_{2}$ nanoparticle formation $\left(\mathrm{TiO}_{2}(\mathrm{~g})\right)$ as well as volatile by-products (water $\left(\mathrm{H}_{2} \mathrm{O}\right)$ and butene $\left.\left(\mathrm{C}_{4} \mathrm{H}_{8}\right)\right)$ in the gas phase (Reaction 1). Subsequently, TBOT undergoes chemical reaction with $\mathrm{H}_{2} \mathrm{O}$ form in Reaction 1 to produce $\mathrm{TiO}_{2}(\mathrm{~g})$ and other volatile by-product (butanol $\left(\mathrm{C}_{4} \mathrm{H}_{9} \mathrm{OH}\right)$ ) also in the gas phase (Reaction 2). Below the thermal decomposition temperature of TBOT reactant, diffusion and convection of TBOT species close to reactor wall occur. TBOT will be adsorbed onto heated reactor wall and heterogeneous reaction occurs at the gas-solid interface producing $\mathrm{TiO}_{2}$ nanoparticles deposit $\left(\mathrm{TiO}_{2}(\mathrm{~s})\right)$ and by-products $\left(\mathrm{H}_{2} \mathrm{O}\right.$ and $\mathrm{C}_{4} \mathrm{H}_{8}$ ) (Reaction 3). $\mathrm{TiO}_{2}(\mathrm{~g})$ formed in Reactions 1 and 2 will undergo chemisorptions on the reactor wall to form $\mathrm{TiO}_{2}(\mathrm{~s})$ (Reaction 4).

Due to lack of data, the activation energy and preexponential factor values for reactions in this study were taken as the values for $\mathrm{TiO}_{2}$ thin films deposited using TTIP (Table 1) [21, 22]. Note that preliminary runs have been carried out to investigate the effect of activation energy on the temperature, carrier gas flowrate, and deposition process whereby the activation energy values were increased up to 5 times that of TTIP. This is due to the fact that experimental work of Conde-Gallardo et al. [15] revealed that the surface activation energy for TBOT $(112.1 \mathrm{~kJ} / \mathrm{mol})$ is about five times that of TTIP $(21.4 \mathrm{~kJ} / \mathrm{mol})$. The results from preliminary runs disclosed that increasing the activation energy barely affected other parameters but reduced the surface deposition rate and amount of yield of $\mathrm{TiO}_{2}$ solid $\left(\mathrm{TiO}_{2}(\mathrm{~s})\right)$. This suggests that using activation energy values of $\mathrm{TiO}_{2}$ thin films deposited using TTIP will not affect much of the fluid dynamics results in present study except for increasing the surface deposition rate and amount of yield. Thus, the mechanism and the qualitative trends will remain essentially valid. 
TABLE 1: Proposed reaction, classification, activation energy, and preexponential factor considered in the model.

\begin{tabular}{|c|c|c|c|}
\hline Proposed reaction & Classification & $\begin{array}{c}\text { Activation energy } \\
(\mathrm{kJ} / \mathrm{mol})\end{array}$ & $\begin{array}{c}\text { Preexponential factor } \\
(1 / s)\end{array}$ \\
\hline (1) $\mathrm{Ti}\left(\mathrm{OC}_{4} \mathrm{H}_{9}\right)_{4} \rightarrow \mathrm{TiO}_{2}(\mathrm{~g})+4 \mathrm{C}_{4} \mathrm{H}_{8}+2 \mathrm{H}_{2} \mathrm{O}$ & Volumetric decomposition & 70.5 & $3.96 \times 10^{5}$ \\
\hline (2) $\mathrm{Ti}\left(\mathrm{OC}_{4} \mathrm{H}_{9}\right)_{4}+2 \mathrm{H}_{2} \mathrm{O} \rightarrow \mathrm{TiO}_{2}(\mathrm{~g})+4 \mathrm{C}_{4} \mathrm{H}_{9} \mathrm{OH}$ & Volumetric hydrolysis & 8.43 & $3.0 \times 10^{15}$ \\
\hline (3) $\mathrm{Ti}\left(\mathrm{OC}_{4} \mathrm{H}_{9}\right)_{4} \rightarrow \mathrm{TiO}_{2}(\mathrm{~s})+4 \mathrm{C}_{4} \mathrm{H}_{8}+2 \mathrm{H}_{2} \mathrm{O}$ & Surface deposition by TBOT & 126.01 & $1.0 \times 10^{9}$ \\
\hline$(4) \mathrm{TiO}_{2}(\mathrm{~g}) \rightarrow \mathrm{TiO}_{2}(\mathrm{~s})$ & Surface deposition by $\mathrm{TiO}_{2}$ & 126.01 & $1.0 \times 10^{9}$ \\
\hline
\end{tabular}

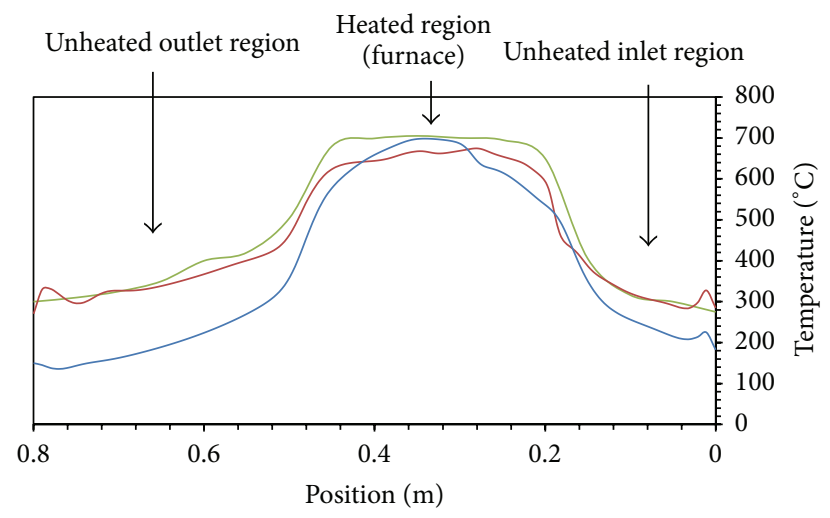

- Manual-without reaction $(\mathrm{M}-\mathrm{R})$

- Simulation-with reactions $(\mathrm{S}+\mathrm{R})$

- Simulation-without reaction $(S-R)$

FIGURE 2: Temperature profiles along the MOCVD reactor for $\mathrm{M}-$ $\mathrm{R}, \mathrm{S}-\mathrm{R}$, and $\mathrm{S}+\mathrm{R}$.

2.3. Simulation Procedure. Geometry and mesh of the modelled MOCVD reactor were generated in Gambit 2.4.6 and exported to computer modelling tool based on CFD called Fluent 12.0. The mesh was a 3D Cartesian grid lying on the $x$ $y-z$ plane. The size of grid was refined in the region close to inlet, outlet, and walls where a larger gradient in temperature, velocity, and species concentrations is expected.

Fluent 12.0 was utilized as the simulator. The code was specifically chosen because of its powerful capability of simulating chemical reactions with exact accuracy compared to other available software such as Phoenics and Flow3D. Fluent employs finite volume method in solving the governing equations which include conservation of mass, momentum, energy, and chemical species. The solver was initialized from the $\mathrm{N}_{2}$ carrier gas and TBOT inlet, which means the conservation equations were solved by using values set at this inlet as the initial values. The flow was considered laminar due to low Reynolds number $(\mathrm{Re}<100)$ calculated according to Reynolds equation.

The temperature at furnace heating zone was assumed to be constant. For quartz tube inner walls, the coupled thermal condition, which is default setting in Fluent, is used. For outer walls (excluding the heating zone), the convection thermal condition is set with a heat transfer coefficient (HTC) of $2 \mathrm{~W} / \mathrm{m}^{2} \mathrm{~K}$. For the gas flow, temperature, mass flow rate, chemical species mass fractions, and flow direction were defined at reactor inlet.
The simulation study was first established with a simple model without any chemical reaction $(-\mathrm{R})$. The model was gradually increased in complexity by adding reactions $(+R)$ and by varying parameters. The heating region was assumed to provide a constant temperature of $700^{\circ} \mathrm{C}$. The reactor was operated at atmospheric pressure of $1 \mathrm{~atm}$. $\mathrm{N}_{2}$ carrier gas entered the reactor at $175^{\circ} \mathrm{C}$ and the flowrate was fixed at $400 \mathrm{~mL} / \mathrm{min}$. Oxygen $\left(\mathrm{O}_{2}\right)$ gas entered the reactor at $27^{\circ} \mathrm{C}$ and the flowrate was fixed at $100 \mathrm{~mL} / \mathrm{min}$. Note that the $\mathrm{O}_{2}$ gas was introduced inside the reactor to reduce carbon impurities that might originate from the precursor, and thus it is not taken into account in the chemical reactions for deposition of $\mathrm{TiO}_{2}$ nanoparticles.

Firstly, the temperature profiles along centre line of reactor without reaction were obtained from CFD simulation (S). It was then compared to the temperature profile obtained by measuring the temperature using thermocouple manually (M). In doing so, the reliability of the CFD simulation results could be established. After that, reactions were included and temperature profiles as well as velocity profiles were compared to those without reaction. This was done to examine the effect of reactions on temperature and velocity inside the reactor. The MOCVD synthesis system was discussed in terms of temperature, velocity, gas streamline, mass fraction of reactants and products, kinetic rate of reaction, and rate of surface deposition profiles.

\section{Results and Discussion}

3.1. Temperature Profiles. Figure 2 compares the temperature profiles of $\mathrm{S}-\mathrm{R}$ and $\mathrm{S}+\mathrm{R}$ at the position along the thermocouple measurement. Also included is the temperature profile of $\mathrm{M}-\mathrm{R}$. It can be seen that the temperature profile of $\mathrm{M}-$ $\mathrm{R}$ is slightly higher than $\mathrm{S}-\mathrm{R}$ especially in the heated region. This is due to the fact that the temperature in heated region inside the reactor has been calibrated to match the desired temperature. Also, there is slight variation in temperature for $\mathrm{M}-\mathrm{R}$ and $\mathrm{S}-\mathrm{R}$ most likely due to the fact that the simulation gave temperature reading every $1 \mathrm{~cm}$ along the thermocouple line while the temperature was measured manually at every $5 \mathrm{~cm}$ using thermocouple. Besides, for CFD simulation, the heat thermal convection at the unheated region was assumed to be $2 \mathrm{~W} / \mathrm{m}^{2} \mathrm{~K}$. Note that although there is slight variation in those two, the trends of the temperature profiles are still comparable. Thus, it can be concluded that the results acquired from the CFD simulation are reliable for further study though there might be slight variation compared to the experimental results. 


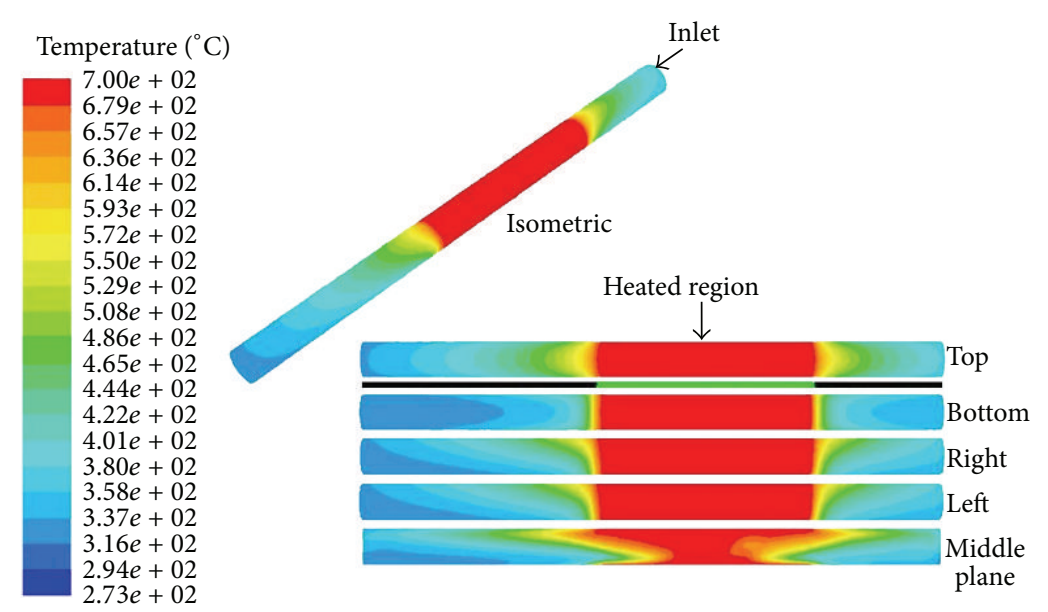

(a)

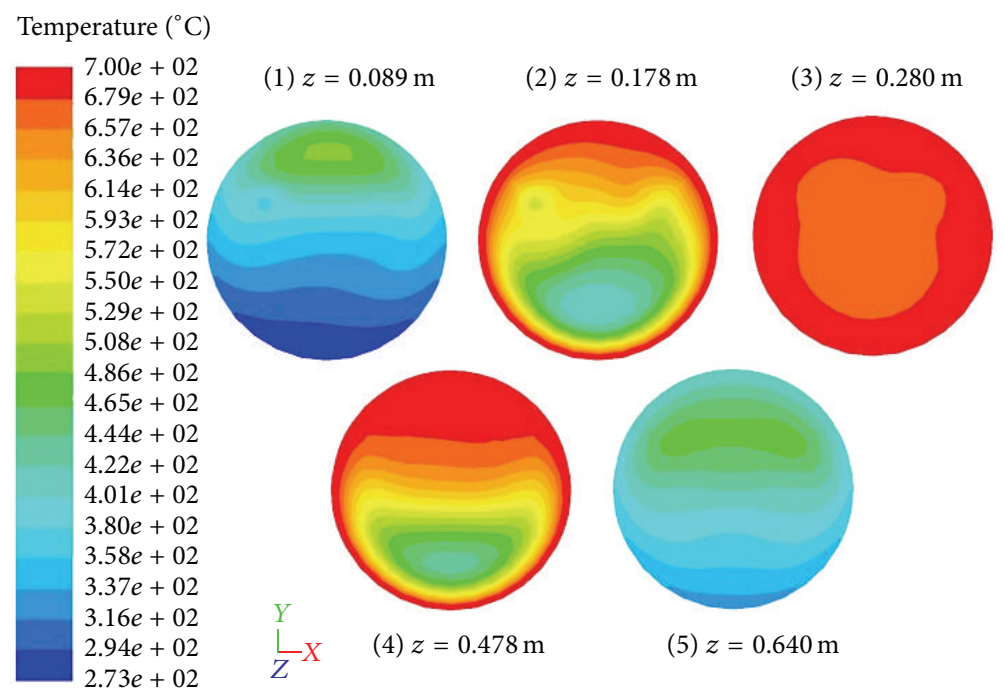

(b)

FIGURE 3: (a) Temperature contours from isometric, top, bottom, right, left, and middle plane viewpoints and (b) radial temperature contours at $z=0.089,0.178,0.478$, and $0.640 \mathrm{~m}$.

When the four reactions tabulated in Table 1 were included in the simulation, the results show that obtained temperature profile of $\mathrm{S}+\mathrm{R}$ follows almost the same trend of $\mathrm{S}-\mathrm{R}$. However, temperature values in the inlet and outlet regions or specifically unheated region for $S+R$ are lower as compared to $\mathrm{S}-\mathrm{R}$. This finding implies that heat in these regions has been used for TBOT thermal decomposition and hydrolysis reactions (endothermic reactions) and consequently, the temperature at these regions decreases.

Figure 3 shows the temperature contours of the $\mathrm{S}+\mathrm{R}$ from isometric, top, bottom, right, left, and middle plane viewpoints as well as the radial temperature contours at $z=0.089$, $0.178,0.280,0.478$, and $0.640 \mathrm{~m}$. The $z$ points were chosen to represent the critical regions inside the reactor $(0.089 \mathrm{~m}-$ middle inlet region (unheated), $0.178 \mathrm{~m}$-boundary entering heated region, $0.280 \mathrm{~m}-$ middle heated region, $0.478 \mathrm{~m}-$ boundary exiting heated region, and $0.640 \mathrm{~m}$ - middle outlet region (unheated)).
The temperature increases rapidly near the furnace entrance and becomes nearly constant in the heated region where furnace temperature is $700^{\circ} \mathrm{C}$ (Figure 3(a)). The temperature contour from the middle plane viewpoint shows that the temperature decreases slightly when approaching middle of the reactor most probably due to heat convection. In fact, this trend can also be observed from radial temperature contour at $z=0.280 \mathrm{~m}$ (Figure 3(b)). Overall, the temperature contours were not axisymmetric (Figure 3 ). The temperature contours near furnace inlet and outlet (Figure 3(a)) appear to have a parabolic pattern which can be related to the gas flow pattern inside reactor that will be discussed later.

Temperature distribution is one of the imperative parameters that will determine the uniformity of deposition [11]. By employing 3D model in CFD simulation study, the temperature distribution inside the reactor can be observed more clearly and more accurately compared to 2D model. Based on the temperature distribution obtained alone, it is expected 

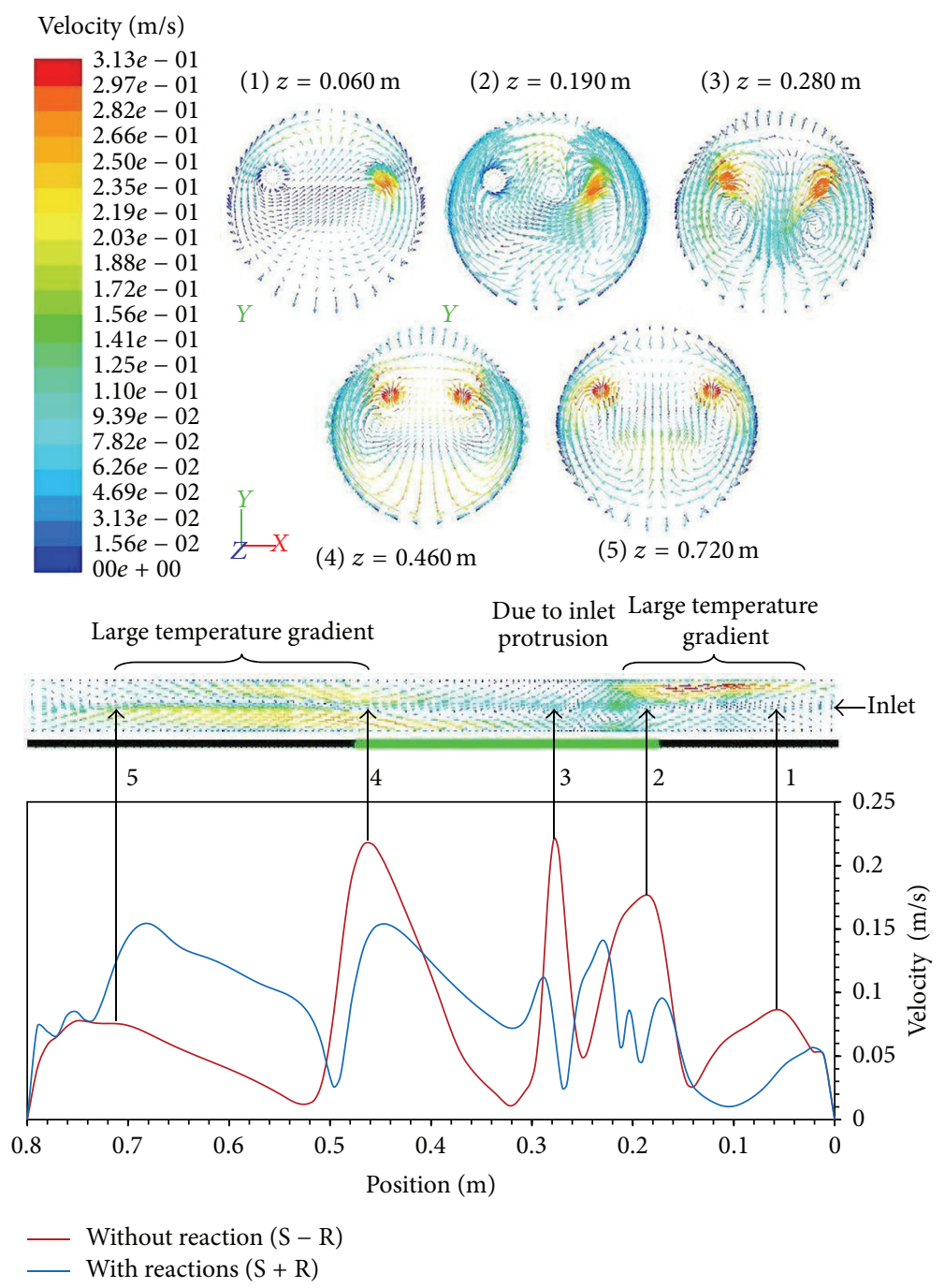

FIgURE 4: Velocity profiles along the reactor for $\mathrm{S}-\mathrm{R}$ and $\mathrm{S}+\mathrm{R}$. Each hump in the velocity profiles of $\mathrm{S}-\mathrm{R}$ is matched with a recirculation loop in the velocity vector profiles of $\mathrm{S}-\mathrm{R}$ (middle plane viewpoint and radials at $z=0.060,0.190,0.280,0.460$, and $0.720 \mathrm{~m}$ ).

for the $\mathrm{TiO}_{2}$ nanoparticles to be deposited uniformly inside the reactor especially in the heated region. Regardless, note that the uniformity of deposition will also be influenced by gas flow velocity and streamlines, mass fraction distribution of reactants and products, and thermophoretic force.

3.2. Velocity Profiles. Figure 4 compares the velocity profiles of $\mathrm{S}-\mathrm{R}$ and $\mathrm{S}+\mathrm{R}$ along the centre line of the reactor. It is obvious that the velocity profiles along centre line of the reactor have anomalous behavior. This is most likely due to the flow recirculation that might arise from inlet protrusion besides the large temperature gradient between heated and unheated regions. The recirculations can be evidenced clearly whereby each hump in the velocity profiles of $S-R$ is matched with a recirculation loop in the velocity vector profiles of $S-R$ (middle plane viewpoint and radials) inside the MOCVD reactor.
It can also be seen that the velocity profile of $S-R$ does not follow the same trend of that of $\mathrm{S}+\mathrm{R}$. This finding is consistent with the fact that more chemical species were introduced to $\mathrm{S}+\mathrm{R}$ and hence more random velocity values. The nominal velocity values along the centre line of the reactor for the $S+R$ are lower as compared to $S-R$ which can be attributed to the lower temperature (Figure 2). The chemical species at low temperature have lower kinetic energy and hence move slower, resulting in lower velocity values. Note that the maximum velocities for $S+R$ and $S$ $-\mathrm{R}$ along centre line of the reactor are 0.154 and $0.221 \mathrm{~m} / \mathrm{s}$, respectively.

The simulated velocity contour and velocity vector profiles of $\mathrm{S}+\mathrm{R}$ inside the MOCVD reactor are shown in Figure 5. It can be observed that there is a recirculation of flow in the unheated inlet region up to furnace entrance (Figure 5(a)) which is due to large temperature difference between the unheated inlet and heated regions of the reactor [23]. This can also be seen from radial velocity vector at $z=$ 


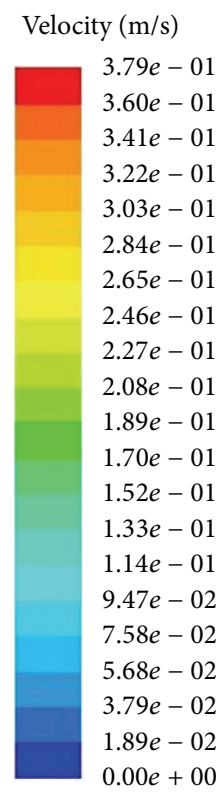

Velocity $(\mathrm{m} / \mathrm{s})$

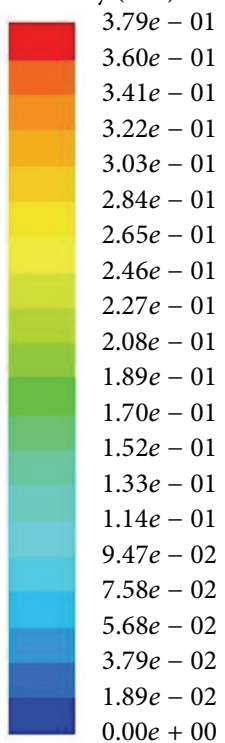

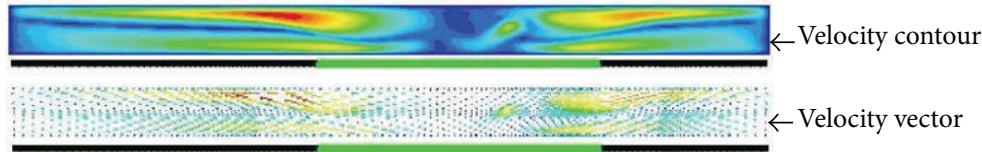
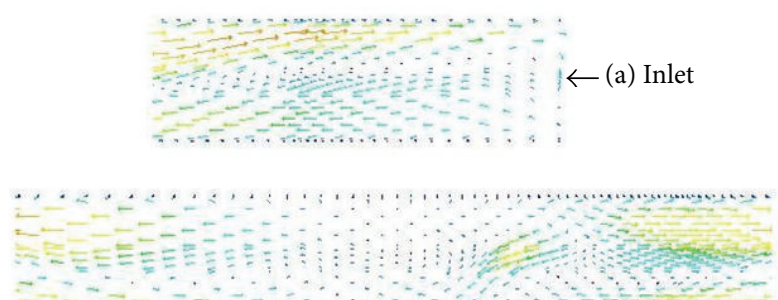

(b) Heated region
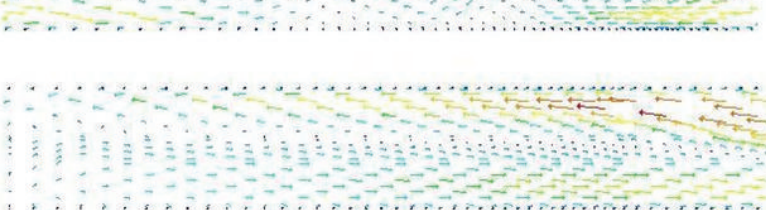

(c) Outlet

(d) Radial velocity vector

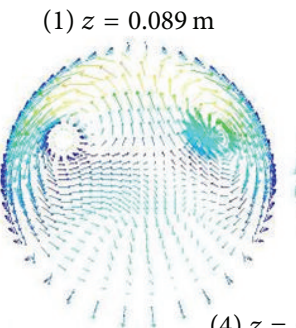

(4) $z=0.478 \mathrm{~m}$

(2) $z=0.178 \mathrm{~m}$
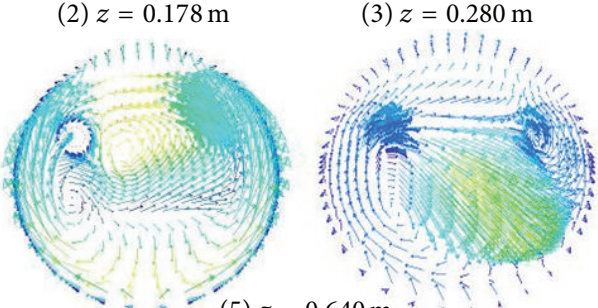

(5) $z=0.640 \mathrm{~m}$ ? ? ?
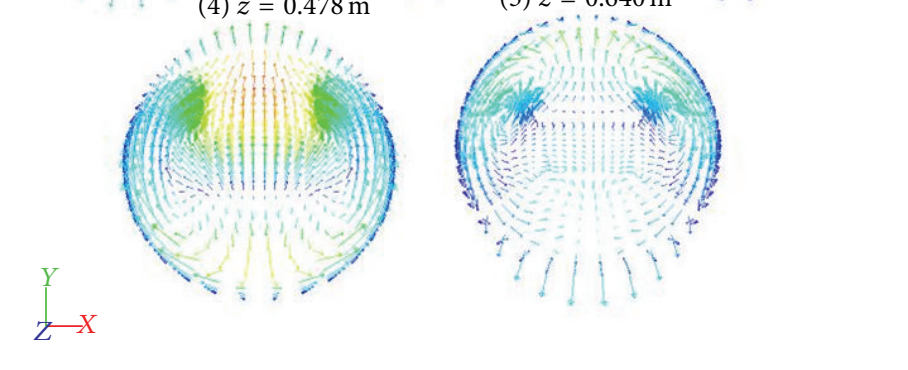

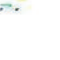

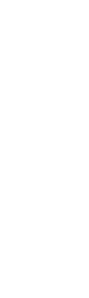


Mass fraction

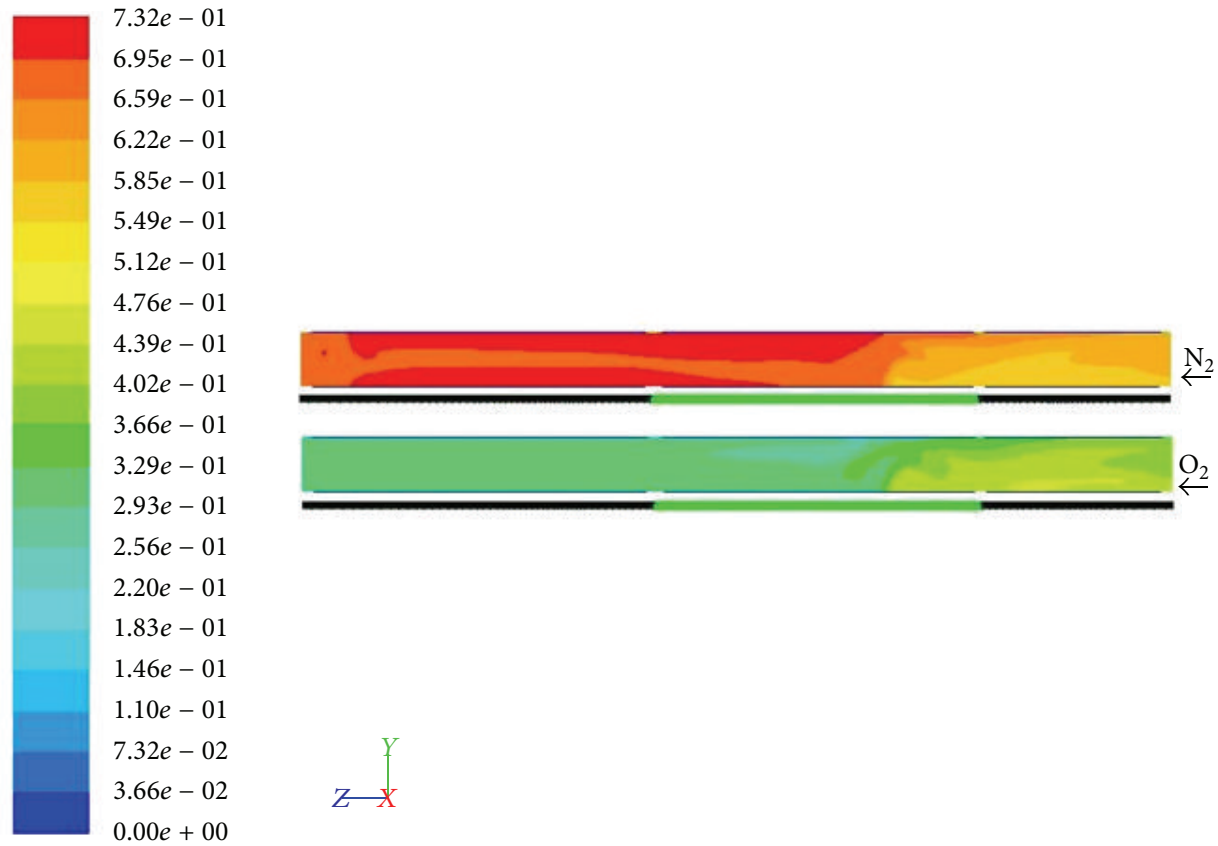

(a) Mass fraction

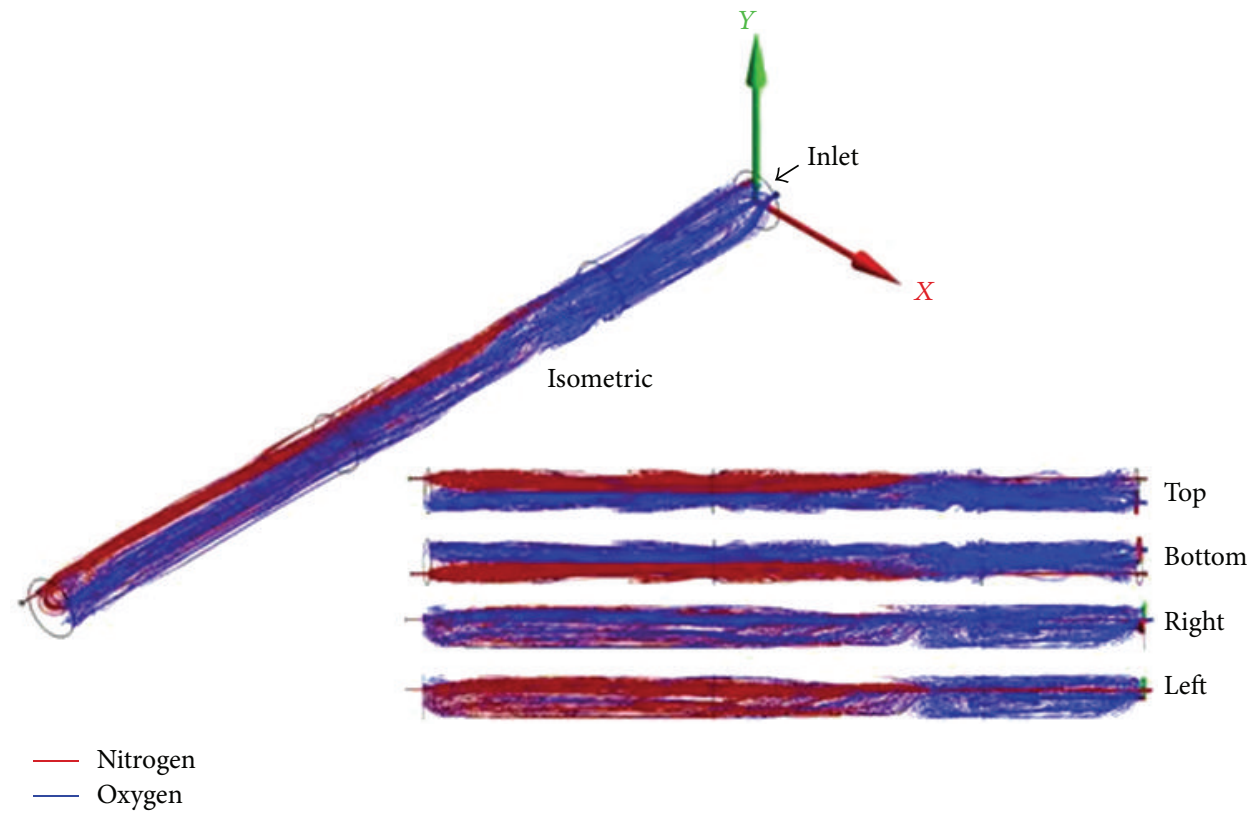

(b) Streamlines

FIgURE 6: (a) Mass fraction contours of $\mathrm{N}_{2}$ and $\mathrm{O}_{2}$ gases from middle plane viewpoint and (b) streamlines of $\mathrm{N}_{2}$ and $\mathrm{O}_{2}$ gases from isometric, top, bottom, right, and left viewpoints.

axisymmetric because of the reactor geometry. Note that since the reactor geometry is nonaxisymmetric, unlike the work of, for example, Baguer et al. [12], one cannot directly observe the parabolic flow pattern in middle of the reactor due to drag forces at the walls which characterizes laminar flow inside the reactor. Nonetheless, the laminar flow inside this model is believed to be true based on the uniformity of flow pattern that can be seen in the heated region.
There is another apparent recirculation of flow from the furnace exit up to the unheated outlet region (Figure 5(c)) which is again due to the large temperature difference between unheated outlet and heated regions of the reactor. Radial velocity vector at $z=0.640 \mathrm{~m}$ (Figure 5(d)) also supports this phenomenon. Apart from that, small outlet at the end of reactor also contributes to the recirculation that occurs near outlet region. 


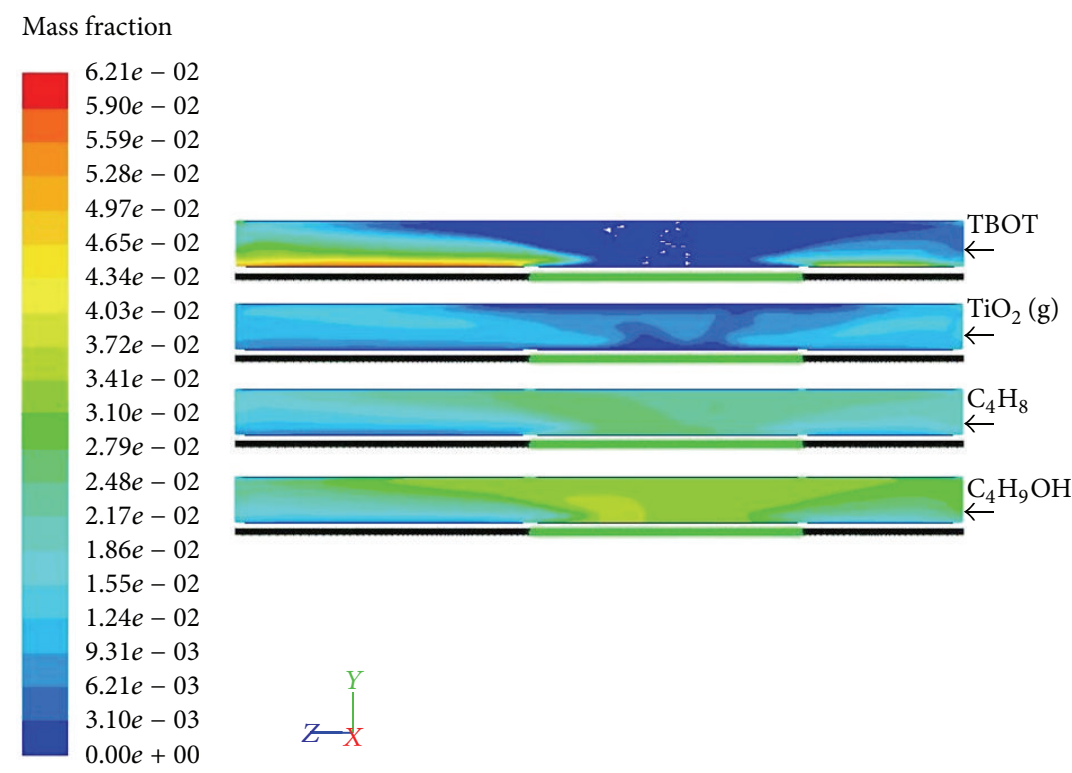

Figure 7: Mass fraction contours of TBOT, $\mathrm{TiO}_{2}(\mathrm{~g}), \mathrm{C}_{4} \mathrm{H}_{8}$, and $\mathrm{C}_{4} \mathrm{H}_{9} \mathrm{OH}$ from the middle plane viewpoint.

3.3. Mass Fraction and Gas Streamline Profiles. Figure 6 shows mass fraction contours and streamlines of $\mathrm{N}_{2}$ and $\mathrm{O}_{2}$ gases inside the reactor. It can be seen that the mass fraction of $\mathrm{N}_{2}$ gas inside the reactor is much higher than that of $\mathrm{O}_{2}$ gas (Figure 6(a)). This can be ascribed to the higher flow rate of $\mathrm{N}_{2}$ gas introduced into the reactor $(400 \mathrm{~mL} / \mathrm{min})$ compared to that of $\mathrm{O}_{2}$ gas $(100 \mathrm{~mL} / \mathrm{min})$. The initial mass fractions of $\mathrm{N}_{2}$ and $\mathrm{O}_{2}$ gases, based on initial flow rate, were found to be around 0.77 and 0.23 , respectively.

Mass fraction of $\mathrm{N}_{2}$ gas is high from the heated region up to the unheated outlet region (Figure 6(a)). This is consistent with the fact that $\mathrm{N}_{2}$ gas is introduced into the reactor in the heated region due to inlet protrusion. Meanwhile, the mass fraction of $\mathrm{O}_{2}$ gas is higher in the unheated inlet region compared to the heated and unheated outlet regions probably due to $\mathrm{O}_{2}$ inlet that is not protruded. Generally, $\mathrm{N}_{2}$ gas is known to be slightly lighter than $\mathrm{O}_{2}$ gas. The temperature of $\mathrm{N}_{2}$ gas $\left(175^{\circ} \mathrm{C}\right)$ introduced into the reactor is much higher than $\mathrm{O}_{2}$ gas $\left(27^{\circ} \mathrm{C}\right)$ which makes $\mathrm{N}_{2}$ gas much lighter than that of $\mathrm{O}_{2}$ gas. Thus, it is easier for $\mathrm{N}_{2}$ gas to travel up to the end of the reactor, resulting in higher mass fraction of $\mathrm{N}_{2}$ gas up to the unheated outlet region than that of $\mathrm{O}_{2}$ gas.

These findings are reflected by the streamlines of both $\mathrm{N}_{2}$ and $\mathrm{O}_{2}$ (Figure 6(b)). The streamline of $\mathrm{N}_{2}$ gas seems to concentrate in the heated and unheated outlet regions while $\mathrm{O}_{2}$ streamline seems to concentrate in the unheated inlet region. Furthermore, the $\mathrm{N}_{2}$ streamline seems to concentrate at left side of the reactor because protruding inlet is located at left side of the reactor. Similarly, $\mathrm{O}_{2}$ streamline seems to concentrate at right side of the reactor because $\mathrm{O}_{2}$ inlet is located at right side of the reactor. These findings could not be attained if the model is simplified to a $2 \mathrm{D}$ model. It is therefore important to model the nonaxisymmetric geometry of MOCVD reactor with 3D model in order to obtain accurate picture of process inside the reactor.

Note that the uniformity of gas distribution could affect the $\mathrm{TiO}_{2}$ produced. It was found from the experimental work that the $\mathrm{TiO}_{2}$ nanoparticles collected at the unheated inlet region were slightly whiter and brighter compared to the nanoparticles collected at the unheated outlet region. This indicated that high $\mathrm{O}_{2}$ concentration available in the unheated inlet region could help to oxidize and reduce carbon impurities that might arise from the precursor. In addition, the amount of $\mathrm{TiO}_{2}$ nanoparticles collected at unheated outlet region was higher than that collected at unheated inlet region because $\mathrm{N}_{2}$ carrier gas that carries TBOT concentrated in the unheated outlet region $(\sim 0.08 \mathrm{~g}$ at inlet region and $\sim$ $0.10 \mathrm{~g}$ at outlet region). These experimental findings further validate the simulation results. Thus, it can be deduced that good mixing of $\mathrm{N}_{2}$ and $\mathrm{O}_{2}$ gases is vital in order to produce impurities-free $\mathrm{TiO}_{2}$ nanoparticles with high photocatalytic efficiency as well as to ensure uniform deposition in terms of amount of yield.

Figure 7 shows the mass fraction contours of TBOT, $\mathrm{TiO}_{2}(\mathrm{~g}), \mathrm{C}_{4} \mathrm{H}_{8}$, and $\mathrm{C}_{4} \mathrm{H}_{9} \mathrm{OH}$ from middle plane viewpoint. From the mass fraction contour of TBOT, it can be seen that TBOT seems to be distributed in the unheated inlet and outlet regions. There is almost no trace of TBOT in high temperature region because the temperature is high enough for TBOT to fully decompose. This finding suggests that Reactions 1-3 will mostly occur at the high temperature region consistent with the finding of Neyts et al. [13]. They found that the TTIP mole fraction decreased at the region of high temperature because gas phase decomposition and the surface reaction were expected to occur in this region. Parabolic pattern contours of TBOT found in the current 


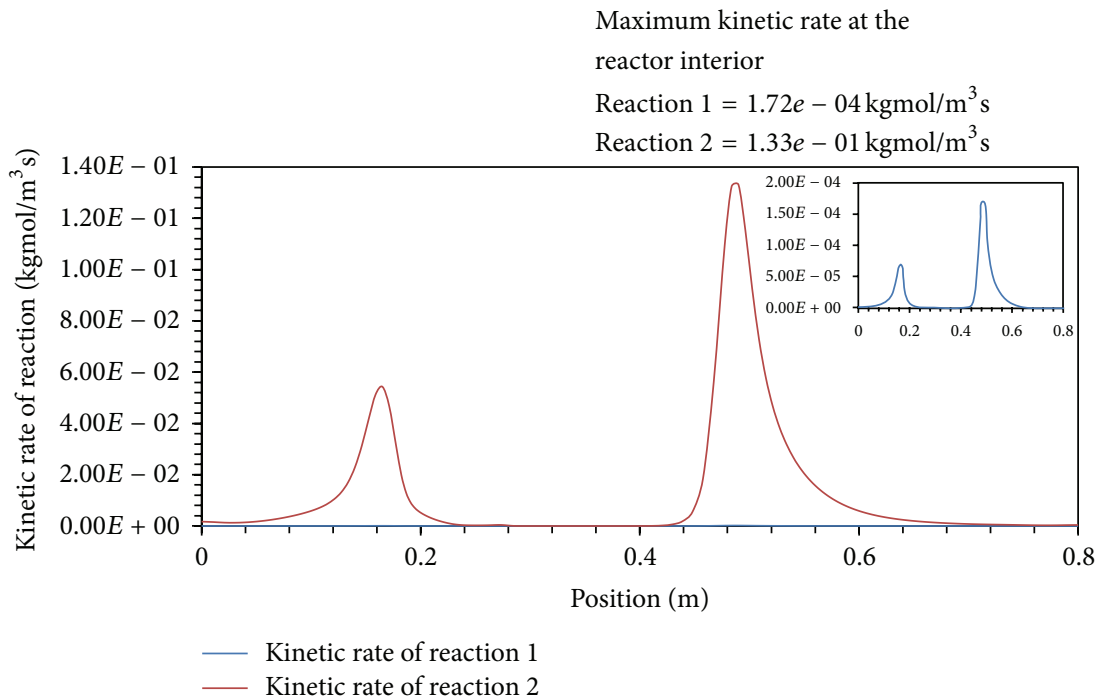

(a) Kinetic rates of reaction

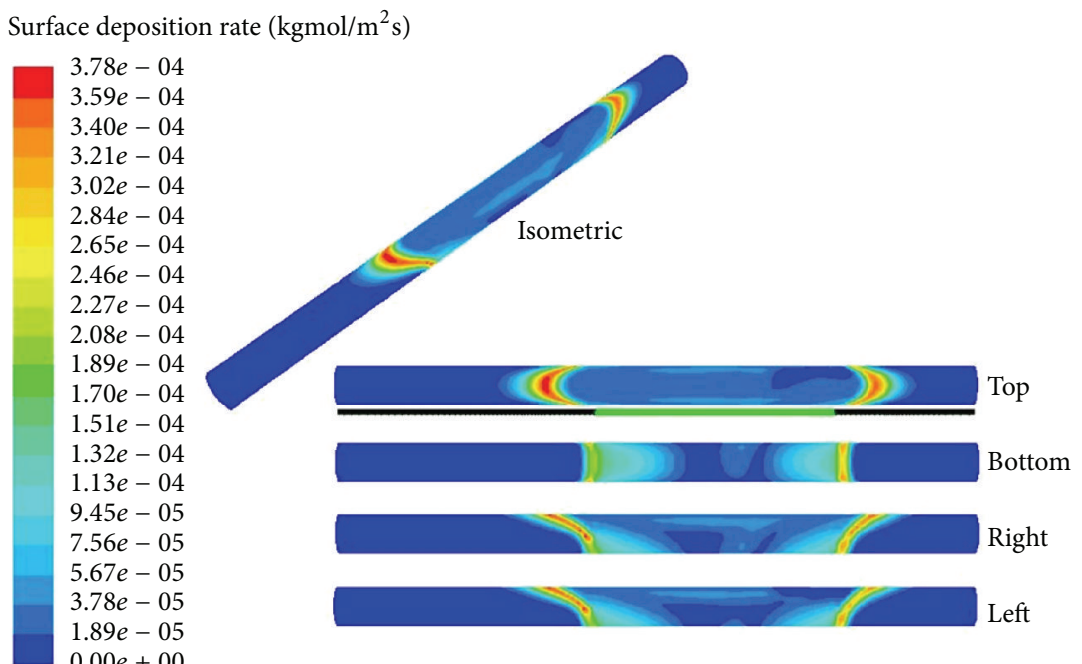

(b) Surface deposition rate $\left(\mathrm{kgmol} / \mathrm{m}^{2} \mathrm{~s}\right)$

Figure 8: (a) Kinetic rates of Reactions 1 and 2 and (b) surface deposition rate contours of $\mathrm{TiO}_{2}(\mathrm{~s})$.

study may be attributed to temperature and gas flow distribution discussed earlier. It can also be seen that the TBOT mass fraction is higher near the bottom of unheated inlet and outlet regions probably because TBOT is dense and heavy and thus tends to settle down at the bottom of reactor.

The mass fraction contour of $\mathrm{TiO}_{2}(\mathrm{~g})$ illustrated that $\mathrm{TiO}_{2}(\mathrm{~g})$ is distributed in almost the entire region of reactor. Unlike TBOT, there is also some $\mathrm{TiO}_{2}(\mathrm{~g})$ in the middle of reactor because $\mathrm{TiO}_{2}(\mathrm{~g})$ is the product of Reactions 1 and 2. However, $\mathrm{TiO}_{2}(\mathrm{~g})$ is more concentrated in unheated inlet and outlet regions especially at the top part of these regions because $\mathrm{TiO}_{2}(\mathrm{~g})$ is lighter and less dense than TBOT thus making it possible for $\mathrm{TiO}_{2}(\mathrm{~g})$ to travel from the heated region to the unheated inlet and outlet regions. This could also be due to heat convection. $\mathrm{TiO}_{2}(\mathrm{~g})$ contour suggests that Reactions 1, 2, and 4 could occur within the entire reactor region and hence $\mathrm{TiO}_{2}$ nanoparticles might be deposited within the whole region. However, the deposition behavior of $\mathrm{TiO}_{2}$ nanoparticles could not be concluded from mass fraction contours alone because it will also be affected by temperature distribution, flow pattern, and thermophoretic force. Again, the parabolic pattern contours may be ascribed to gas flow and temperature distribution.

Note that $\mathrm{C}_{4} \mathrm{H}_{8}$ is the product of Reactions 1 and 3 while $\mathrm{C}_{4} \mathrm{H}_{9} \mathrm{OH}$ is the product of Reaction 2. Mass fraction contours of $\mathrm{C}_{4} \mathrm{H}_{8}$ and $\mathrm{C}_{4} \mathrm{H}_{9} \mathrm{OH}$ show that most of them are distributed at the region where $\mathrm{TBOT}$ and $\mathrm{TiO}_{2}(\mathrm{~g})$ are at their lowest concentration. This is because both of these gases are lighter and less dense compared to TBOT and $\mathrm{TiO}_{2}(\mathrm{~g})$ and therefore they rise up and concentrate in these regions. Moreover, mass fraction of $\mathrm{C}_{4} \mathrm{H}_{8}$ is lower than that of $\mathrm{C}_{4} \mathrm{H}_{9} \mathrm{OH}$ probably because activation energy of Reaction 2 is lower than that of Reactions 1 and 3. This implies that Reaction 2 dominated Reactions 1 and 3 and thus lowered 
mass fraction of $\mathrm{C}_{4} \mathrm{H}_{8}$ product. Meanwhile, the $\mathrm{H}_{2} \mathrm{O}$ mass fraction contour is not shown because concentration of $\mathrm{H}_{2} \mathrm{O}$ species inside the reactor is almost negligible and could not be observed from middle plane viewpoint. This must be due to very high temperature inside the reactor $\left(>100^{\circ} \mathrm{C}\right)$.

\subsection{Kinetic Rate of Reaction and Surface Deposition Profiles.} The kinetic rates of Reactions 1 and 2 along centre line of the reactor and surface deposition contours of $\mathrm{TiO}_{2}(\mathrm{~s})$ are shown in Figure 8. The inset shows the kinetic rate of Reaction 1 in smaller scale (Figure 8(a)). It can be seen that the kinetic rates of Reactions 1 and 2 seem to be at maximum values, close to the regions entering $(0.16 \mathrm{~m})$ and exiting $(0.48 \mathrm{~m})$ heated region of the reactor (Figure $8(\mathrm{a})$ ) suggesting that most of $\mathrm{TiO}_{2}$ (s) will be deposited at these regions. The maximum kinetic rates of Reactions 1 and 2 inside the reactor are, respectively, found to be $1.72 \times 10^{-4}$ and $1.33 \times 10^{-1} \mathrm{kgmol} / \mathrm{m}^{3} \mathrm{~s}$ which indicates that Reaction 2 dominates Reaction 1 . This is consistent with the fact that activation energy of Reaction 2 is much lower than that of Reaction 1 thus lowering the amount of energy required for Reaction 2 to occur. This result is supported by the finding of Baguer et al. [12]. They found that hydrolysis reaction of TTIP became predominant over the gas thermal decomposition under all conditions investigated.

Meanwhile, the maximum kinetic rates of Reactions 3 and 4 were found to be $1.35 \times 10^{-6}$ and $4.61 \times 10^{-6} \mathrm{kgmol} / \mathrm{m}^{2} \mathrm{~s}$, respectively, implying that Reaction 4 dominates Reaction 3. This indicates that most of the TBOT has been used for Reactions 1 and 2 due to lower activation energy values if compared to Reaction 3. As a result, the amount of $\mathrm{TiO}_{2}(\mathrm{~g})$ increases because $\mathrm{TiO}_{2}(\mathrm{~g})$ is product of Reactions 1 and 2 . Thus, more $\mathrm{TiO}_{2}(\mathrm{~g})$ is available for Reaction 4 to occur. Note that it is not possible to show the plots of kinetic rates of Reactions 3 and 4 along centre line of the reactor because $\mathrm{TiO}_{2}$ (s) formation (surface reaction) occurs at the reactor wall. The best way to present the $\mathrm{TiO}_{2}$ (s) formation using CFD simulation is by surface deposition rate contour.

The surface deposition rate contour could not be obtained if the model was simplified to a $2 \mathrm{D}$ model. The surface deposition rate contour obtained from $3 \mathrm{D}$ reactor model provides advantage of better picturing deposition uniformity, deposition location, and amount of yield. The higher the surface deposition rate, the more the amount of yield obtained.

In addition, the surface deposition rate of $\mathrm{TiO}_{2}(\mathrm{~s})$ is the highest near the regions entering and exiting the heated region of reactor (Figure $8(\mathrm{~b})$ ) implying that most of the $\mathrm{TiO}_{2}(\mathrm{~s})$ is deposited in these regions. This finding is in agreement with the experimental finding whereby most of the $\mathrm{TiO}_{2}$ nanoparticles were deposited at these regions. The parabolic pattern of surface deposition may be ascribed to the fact that distribution of product follows the pattern of temperature. Comparing the temperature and surface deposition patterns (Figure 3 and Figure 8(b)), it could be observed that the rate of surface deposition of $\mathrm{TiO}_{2}(\mathrm{~s})$ is maximum at region where high temperature in the heated region starts to decrease. This is due to thermophoretic deposition, where temperature gradient imposes thermophoretic force on the particles. As a result, the particles move from high to low temperature regions and deposit at low temperature region [28, 29]. There is also some $\mathrm{TiO}_{2}(\mathrm{~s})$ deposit at the heated region because temperature at this region is high enough for TBOT to fully decompose and form $\mathrm{TiO}_{2}(\mathrm{~s})$.

\section{Conclusion}

The MOCVD synthesis system of $\mathrm{TiO}_{2}$ nanoparticles deposited using TBOT precursor was successfully simulated by means of CFD. The 3D model was simulated to predict temperature, velocity, gas streamlines, mass fractions of reactants and products, kinetic rates of reaction, and surface deposition rate profiles inside the horizontal configuration MOCVD reactor.

The temperature appeared to have parabolic pattern which can be related to heat convection and gas flow pattern. Recirculations occurred during the synthesis process due to large temperature gradient between the heated and unheated regions as well as inlet protrusion. Reaction with low activation energy (Reaction 2) dominated reaction with high activation energy (Reaction 1) due to less energy needed for the reaction to occur. Thus, Reaction 2 has higher kinetic rate and produced higher amount of products than that of Reaction 1.

The influence of fluid dynamics on deposition process was also explored. The maximum surface deposition rate of $\mathrm{TiO}_{2}$ nanoparticles was found to be $3.78 \times 10^{-4} \mathrm{kgmol} / \mathrm{m}^{2} \mathrm{~s}$. The deposition behavior of $\mathrm{TiO}_{2}$ nanoparticles was significantly affected by temperature distribution, flow pattern, and thermophoretic force. It was found that good mixing of $\mathrm{N}_{2}$ and $\mathrm{O}_{2}$ gases is important to produce impurities-free $\mathrm{TiO}_{2}$ nanoparticles with high photocatalytic efficiency as well as to ensure uniform deposition.

\section{Acknowledgment}

This work was financially supported by Fundamental Research Grant Scheme, University Putra Malaysia (Grant no. 5523426).

\section{References}

[1] Y. Wang, Y. Xie, J. Yuan, and G. Liu, "Controlled synthesis and photocatalytic activity of $\mathrm{TiO}_{2}$ nanoparticles by a novel gelnetwork precipitation method," Asian Journal of Chemistry, vol. 25, no. 2, pp. 739-744, 2013.

[2] A. K. Tripathi, M. K. Singh, M. C. Mathpal, S. K. Mishra, and A. Agarwal, "Study of structural transformation in $\mathrm{TiO}_{2}$ nanoparticles and its optical properties," Journal of Alloys and Compounds, vol. 549, pp. 114-120, 2013.

[3] P. Yuthavisuthi, L. Jarupan, and C. Pechyen, "Modification of mechanical properties by $\mathrm{TiO}_{2}$ nano-particle for biodegradable materials made from palm oil sludge and activated sludge cake," Transactions of Nonferrous Metals Society of China, vol. 22, pp. s697-s701, 2012.

[4] Y. Lin, Z. Jiang, C. Zhu et al., "Electronic and optical performances of $\mathrm{Si}$ and $\mathrm{Fe}$-codoped $\mathrm{TiO}_{2}$ nanoparticles: a photocatalyst for the degradation of methylene blue," Applied Catalysis B, vol. 142-143, pp. 38-44, 2013. 
[5] H. Li, H. Deng, and J. Zhao, "Performance research of polyester fabric treated by nano Titanium Dioxide $\left(\mathrm{Nano}^{-\mathrm{TiO}_{2}}\right)$ antiultraviolet finishing," International Journal of Chemistry, vol. 1, no. 1, pp. 57-62, 2009.

[6] K. Brandt, V. Salikov, H. Özcoban et al., "Novel ceramicpolymer composites synthesized by compaction of polymerencapsulated $\mathrm{TiO}_{2}$-nanoparticles," Composites Science and Technology, vol. 72, no. 1, pp. 65-71, 2011.

[7] Y. S. Kim, P. Rai, and Y. T. Yu, "Microwave assisted hydrothermal synthesis of $\mathrm{Au} @ \mathrm{TiO}_{2}$ core-shell nanoparticles for high temperature CO sensing applications," Sensors and Actuators B, vol. 186, pp. 633-639, 2013.

[8] G. Cheng, M. S. Akhtar, O. B. Yang, and F. J. Stadler, "Novel preparation of anatase $\mathrm{TiO}_{2} @$ reduced Graphene Oxide hybrids for high-performance dye-sensitized solar cells," ACS Applied Materials and Interfaces, vol. 5, no. 14, pp. 6635-6642, 2013.

[9] W. Li, S. Ismat Shah, C.-P. Huang, O. Jung, and C. Ni, "Metallorganic chemical vapor deposition and characterization of $\mathrm{TiO}_{2}$ nanoparticles," Materials Science and Engineering B, vol. 96, no. 3, pp. 247-253, 2002.

[10] X. Zhang, M. Zhou, and L. Lei, "Preparation of photocatalytic $\mathrm{TiO}_{2}$ coatings of nanosized particles on activated carbon by APMOCVD," Carbon, vol. 43, no. 8, pp. 1700-1708, 2005.

[11] Z. Nami, O. Misman, A. Erbil, and G. S. May, "Computer simulation study of the MOCVD growth of titanium dioxide films," Journal of Crystal Growth, vol. 171, no. 1-2, pp. 154-165, 1997.

[12] N. Baguer, E. Neyts, S. Van Gils, and A. Bogaerts, "Study of atmospheric MOCVD of $\mathrm{TiO}_{2}$ thin films by means of computational fluid dynamics simulations," Chemical Vapor Deposition, vol. 14, no. 11-12, pp. 339-346, 2008.

[13] E. Neyts, A. Bogaerts, M. De Meyer, and S. Van Gils, "Macroscale computer simulations to investigate the chemical vapor deposition of thin metal-oxide films," Surface and Coatings Technology, vol. 201, no. 22-23, pp. 8838-8841, 2007.

[14] Z. Nami, O. Misman, A. Erbil, and G. S. May, "Effect of growth parameters on $\mathrm{TiO}_{2}$ thin films deposited using MOCVD," Journal of Crystal Growth, vol. 179, no. 3-4, pp. 522-538, 1997.

[15] A. Conde-Gallardo, N. Castillo, and M. Guerrero, "Growth kinetics of $\mathrm{TiO}_{2}$ films deposited by aerosol-assisted chemicalvapor deposition from two different precursors (Ti-n-butoxide and Ti diisopropoxide)," Journal of Applied Physics, vol. 98, no. 5, Article ID 054908, 2005.

[16] P. Falaras and A. P. Xagas, "Roughness and fractality of nanostructured $\mathrm{TiO}_{2}$ films prepared via sol-gel technique," Journal of Materials Science, vol. 37, no. 18, pp. 3855-3860, 2002.

[17] S. H. Othman, S. Abdul Rashid, T. I. Mohd Ghazi, and N. Abdullah, "Effect of postdeposition heat treatment on the crystallinity, size, and photocatalytic activity of $\mathrm{TiO}_{2}$ nanoparticles produced via chemical vapour deposition," Journal of Nanomaterials, vol. 2010, Article ID 512785, 10 pages, 2010.

[18] S. H. Othman, S. A. Rashid, T. I. M. Ghazi, and N. Abdullah, "Effect of fe doping on phase transition of $\mathrm{TiO}_{2}$ nanoparticles synthesized by MOCVD," Journal of Applied Sciences, vol. 10, no. 12, pp. 1044-1051, 2010.

[19] S. Abdul Rashid, S. H. Othman, T. I. Mohd Ghazi, and N. Abdullah, "Fe-doped $\mathrm{TiO}_{2}$ nanoparticles produced via MOCVD: synthesis, characterization, and photocatalytic activity," Journal of Nanomaterials, vol. 2011, Article ID 571601, 2011.

[20] S. H. Othman, S. Abdul Rashid, T. I. Mohd. Ghazi, and N. Abdullah, " $\mathrm{TiO}_{2}$ Nanoparticles prepared by MOCVD: effect of temperature, flowrate, and precursor," Asia-Pacific Journal of Chemical Engineering, vol. 8, no. 1, pp. 32-44, 2012.

[21] N. Baguer, E. Neyts, S. Van Gils, and A. Bogaerts, "Study of atmospheric MOCVD of $\mathrm{TiO}_{2}$ thin films by means of computational fluid dynamics simulations," Chemical Vapor Deposition, vol. 14, no. 11-12, pp. 339-346, 2008.

[22] E. Neyts, A. Bogaerts, M. De Meyer, and S. Van Gils, "Macroscale computer simulations to investigate the chemical vapor deposition of thin metal-oxide films," Surface and Coatings Technology, vol. 201, no. 22-23, pp. 8838-8841, 2007.

[23] J. Ouazzani, K.-C. Chiu, and F. Rosenberger, "On the 2D modelling of horizontal CVD reactors and its limitations," Journal of Crystal Growth, vol. 91, no. 4, pp. 497-508, 1988.

[24] J. Ouazzani and F. Rosenberger, “Three-dimensional modelling of horizontal chemical vapor deposition-I. MOCVD at atmospheric pressure," Journal of Crystal Growth, vol. 100, no. 3, pp. $545-576,1990$

[25] T. S. Cheng and M. C. Hsiao, "Computation of threedimensional flow and thermal fields in a model horizontal chemical vapor deposition reactor," Journal of Crystal Growth, vol. 293, no. 2, pp. 475-484, 2006.

[26] Y. C. Chuang and C. T. Chen, "Mathematical modeling and optimal design of an MOCVD reactor for GaAs film growth," Journal of the Taiwan Institute of Chemical Engineers, 2013.

[27] K. Li, L. Zhang, D. A. Dixon, and T. M. Klein, "Undulating topography of $\mathrm{HfO}_{2}$ thin films deposited in a mesoscale reactor using hafnium (IV) tert butoxide," AIChE Journal, vol. 57, no. 11, pp. 2989-2996, 2011.

[28] D. Gonzalez, A. G. Nasibulin, A. M. Baklanov et al., "A new thermophoretic precipitator for collection of nanometer-sized aerosol particles," Aerosol Science and Technology, vol. 39, no. 11, pp. 1064-1071, 2005.

[29] P. Biswas and C.-Y. Wu, "Nanoparticles and the environment," Journal of the Air and Waste Management Association, vol. 55, no. 6, pp. 708-746, 2005. 

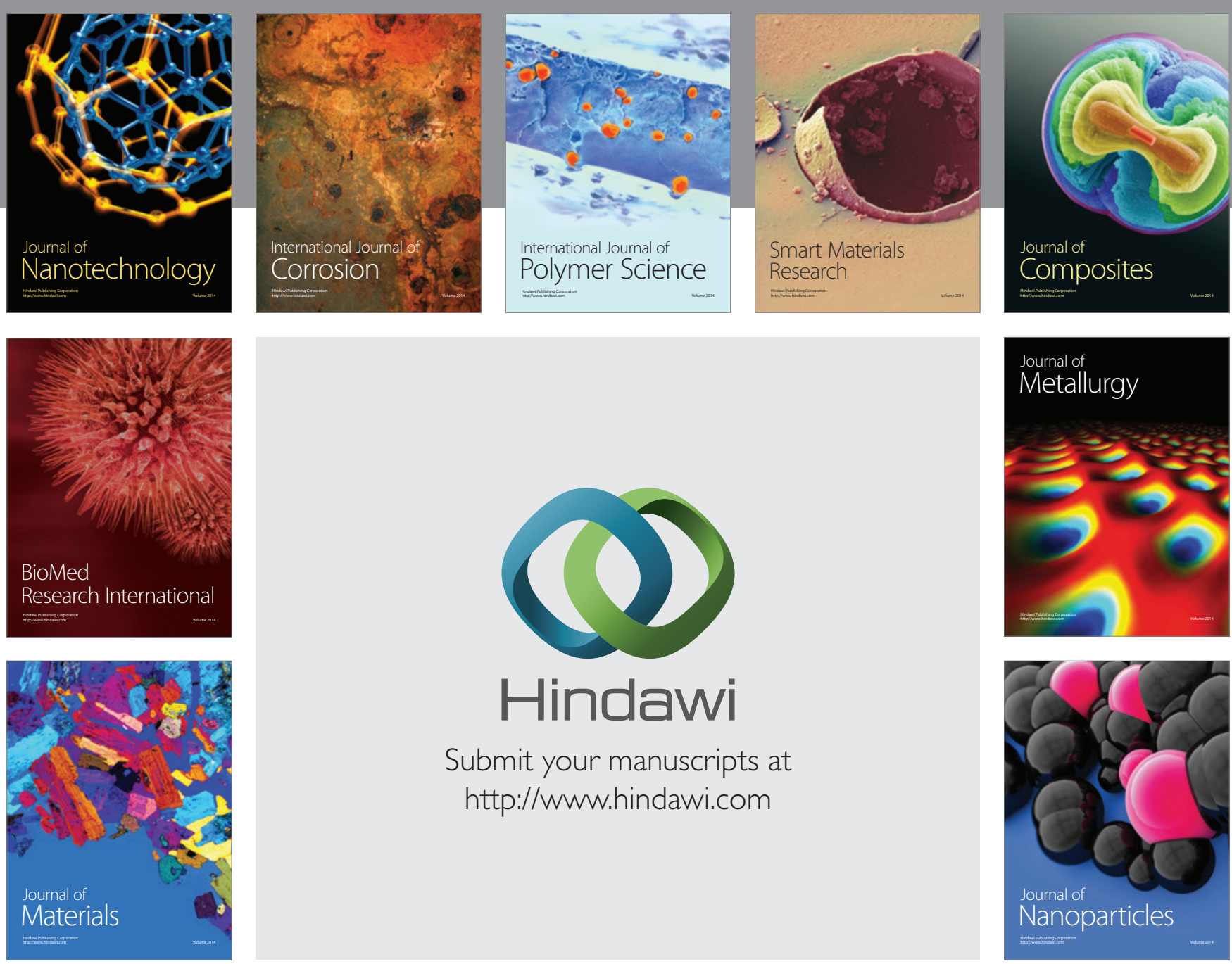

Submit your manuscripts at http://www.hindawi.com
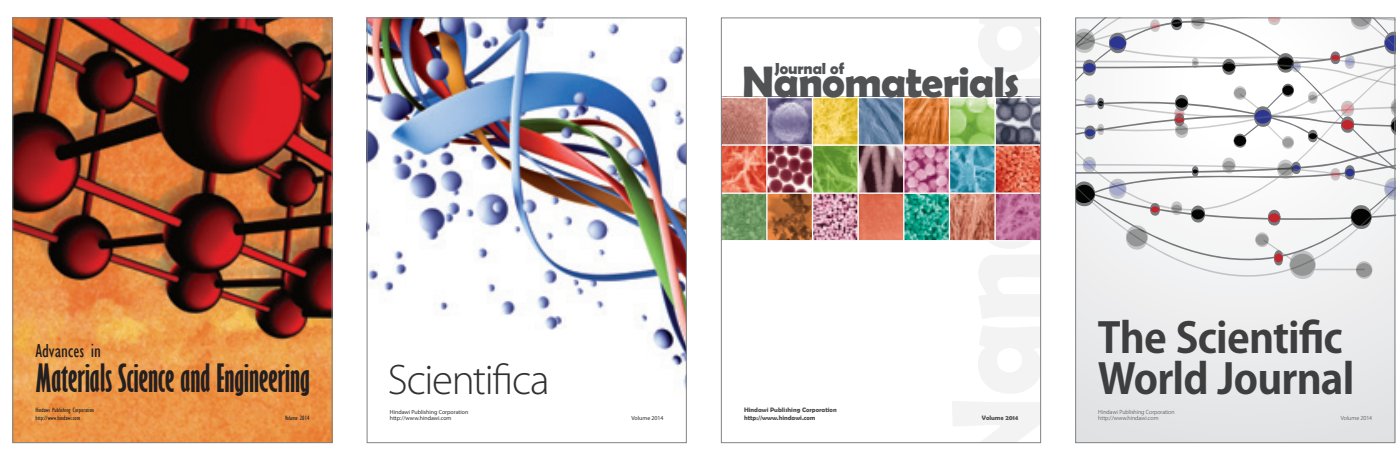

\section{The Scientific World Journal}
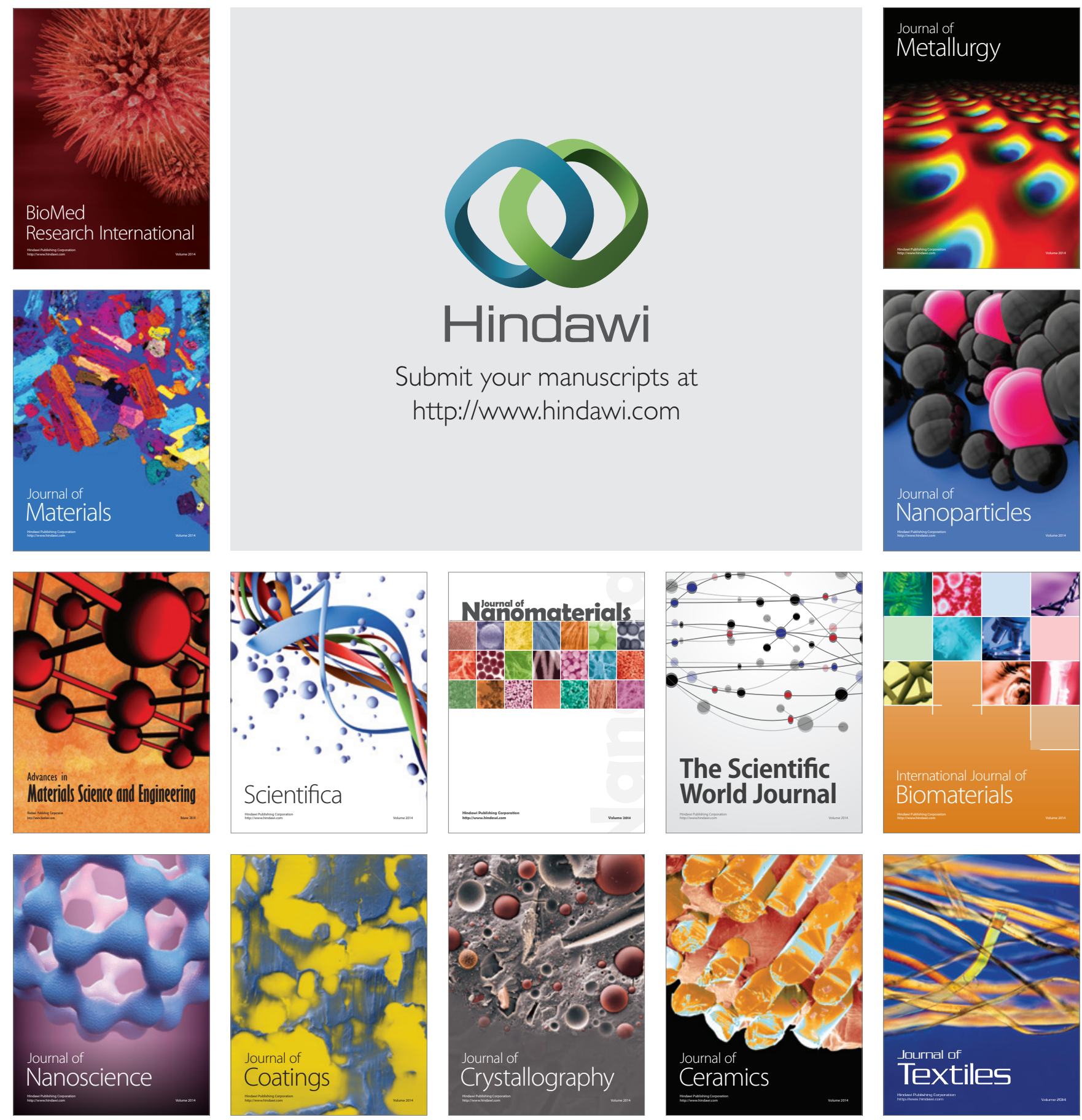